\title{
Global Risks Networks: A New Field of Interdisciplinary Studies
}

\author{
Oleg N. Yanitsky* \\ Doctor of Philosophy, Professor, Chief Researcher, the Federal Center of Theoretical and Applied Sociology of \\ the Russian academy of sciences. Address: 117218, Moscow, Krzizhanovskogo str., 24/35, b.5
}

*Corresponding Author: Oleg N. Yanitsky, Doctor of Philosophy, Professor, Chief Researcher, the Federal Center of Theoretical and Applied Sociology of the Russian academy of sciences. Address: 117218, Moscow, Krzizhanovskogo str., 24/35, b.5. Email: oleg.yanitsky@yandex.ru

\begin{abstract}
The article represents the analysis and reflections on a series of global risks researches carried out by an international team of experts during 10 years by the initiative of the World Economic forum in 20082018s. Drawing on the material of these Reports and on the investigations of global structures and processes carried out by world scientific community at the turn of XX and XXI centuries the author came to the following conclusions. It is a first empirical study of global risks networks and the emergence of critical situations at the points of their intersection. Modern risks are complex phenomenon mainly of man-made origin that cannot be reduced to the sum of parallel processes. Potentially, the global risks are a multisided, all-embracing and all-penetration phenomenon that should be studied by means of interdisciplinary methodology. The study of space-time regime of the intersection of interests of global and local stakeholders is very important because it assists to reveal and analyze a multitude of metabolic processes. Risks may produce a cascade effects that is a succession of negative natural, social and technological events and environment destruction. Risks as a threat may be direct or indirect, and exert immediate or postponed effect. I distinguish actual and sleeping (overt), or even false(dramatized) risks. An intensification of market economy is usually resulted in an overexploitation of the planet resources that is risky in its nature. All said above means a necessity of development of analysis of global risks as a highly complicated sociobiotechnical system (hereafter the SBT-system) full of metabolic transformations. The shaping of global SBT-system means that the threshold of the biosphere sustainability had been surmounted.
\end{abstract}

Keywords: Civil Activism, Critical Points, Feedback, Globalization, Interdisciplinary Approach, Market Economy, Metabolism, Networks, Risks, Time-Space Rhythms, Sustainability, The SBT-System, Virtualization

\section{INTRODUCTION}

The following text represents the analysis and reflections on a series of global risks research carried out by an international team of experts during 10 years (Global risk Report 2018). My analysis and reflections is focused on a global network structure of various actors and their impact on different realms of natural and social environment. This analysis has revealed some critical points on the intersections of some of the above networks. This unique international research is aimed at more detailed comprehension of the picture of world dynamics of the last ten years. These reports were based on experts' investigation backed by global statistics. This long-term study signifies a new stage in global research at large. Global risks are highly complicated SBT-system full of twists, unintended consequences and metabolic transformations.

My reflections as a sociologist and environmentalist are related to the major outcomes of this longitude accompanied by some critical remarks and suggestions concerning possible prospects of such global risks research. In particular, I see necessary to compile more complicated (not linear and mechanic-like) picture of global processes and networks, to comprehend this network structure as carrying functional structure of globalization process as a whole, and to make a step forward in the development of global sociology which is dealing with not only with 'opinions' and one-sided 'interactions' but with rather complicated transformations of the global SBT system (Yanitsky, 2016: 123-135) in space and time.

\section{RISK DEFINITION}

In modern sociological literature there is a variety of risk definition (see, for example, Adam et al., 1994; Lash et al., 1996; Therborn, 2000, 2013). In this article I follow the definition offered by U. 
Beck who stated that 'Risk is the modern approach to foresee and control the future consequences of human action, the various unintended consequences of radicalized modernization' aimed at of colonization of the future. The risk 'regime is a function of a new order: it is not national, but global... Risk society theory breaks with...self-sufficiency and self-centeredness.' And risk society needs an interdisciplinary approach (Beck, 1999: 3-4). Beck underscored that globalization doesn't mean a global equality of risk. On the contrary, 'the first law of environmental risks is: pollution follows the poor' and 'free-market ideology has increased the sum of human misery' (Beck, 1999: 5). Beck and his followers including me maintains that the global market economy and its ideologues ate the main constructors of so-called 'organized irresponsibility' when nobody capable to control global market. As Chernobyl and Fukusima-1 showed, such irresponsibility may generate the anthropological shock. Modern risks are transformable, for example, social risks may initiate ecological ones and so on. In parallel, global market economy is rapidly politicized. Finally, Z. Bauman, U. Beck, J. Urry and other risk-researchers draw our attention to a new mean of the notion of 'individualism.' As Bauman stated, the coming global society is an individualized society in which a family and local community are losing its significance as a primary eco-structure as a mean of permanent socialization (Bauman 2001, 2001a; Yanitsky, 2012). As Beck rightly stated the most of the rights and entitlements are designed for individuals and not for families and communities, and speaking in more general terms, current global community is undermining its basic moral foundations. The abovementioned and many other features of global risk society lead us to non-linear concept of knowledge production focused not only on its distribution but on the 'distribution of unawareness of unintended consequences' as well (Beck, 1999: 127). All said above means that we are living in the age of constructivism with unintended consequences and uncertainties. It is two sides of the same coin. Nevertheless, I agree with Beck that many risk theorists do not recognize the opportunities of the risk society that is the risks may produce the 'goods' in the Beck's terminology.

Being agreed with the above theorists, as a sociologist I'd like to underscore that risk is a social action making harm to other actors. Besides, to my mind, any kind of environment is a collective actor as well, be it natural, social or technical phenomena.

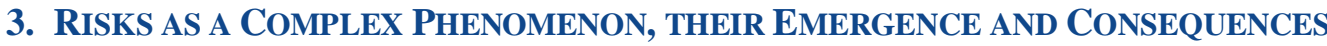

From ancient times and up to now risks (as a threat) were produced by various forces, cosmic, natural and social ones. In the course of humanity development risks production and dissemination of their consequences has become more and more man-made ones. The main reasons of this shift were various ranging from the growth of world population and continuing mastering of new lands by means of technological inventions to the wars and natural and man-made disasters.

But the complexity of risks cannot be reduced to their multisided nature. The further the humanity masters our planet the more complex the risks have become. The matter is that the integrity of the man-made structures and processes was growing and risky consequences of their transformations had accumulated in all spheres of natural and social environment. And not only had accumulated but continued to exert impact on other spheres of natural and human life.

Another distinguishing feature of the risks 'behavior' is their not well-understandable space-time regime. Some forces have act promptly, others not immediately and much more slow, and an impact of still others is not well detectable at all. From the theoretical viewpoint it means that a researcher has to pay attention to space-time regime of risks production and dissemination. Besides, various types of risks may have a specific space-time rhythm of their dissemination and a character of an asynchronous impact which they exert on a particular environment and on its flora, fauna and inhabitants.

In modern societies risks may produce a cascade effects. Say, a hurricane or long-term rains may destruct some types of industrial or agricultural production, that in turn will negatively affects rural and urban population, this population will migrate to large cities or to other rural areas, etc. If local population is divided in casts or if there is any other ethnic or religious barriers the influx of migrants (strangers) may generate ethno-confessional conflicts and even local wars.

It is reasonable to distinguish actual and sleeping or overt risks. Any process of production and reproduction of a society is usually accompanied by risks generation. If a society or their clusters is functioning in a more or less 'normal' regime, the risks production is possible to mitigate. But if the 
society is working in a kind of critical regime some 'sleeping' risks like human resentments generated by lack of living standards, quality of a secondary or higher school education the sleeping risks may take a form of mass protest actions, strikes, etc. That is, under the above conditions the risks produce various forms of a feedback, or using the words of U. Beck, a 'boomerang effect.' Such boomerangs may cost (in terms of time, money and human dissatisfaction) much more than the 'normal' investments; for example, in the run of construction of a neighborhood or any other form of human settlement. But civil war is usually a permanent and multisided risk with a lot of unintended consequences.

Any form of market economy burdened with risks because its indispensable feature is exploitation of natural and human resources. Any form of intensification of market economy is resulted in overexploitation of the above resources that is risky in its very nature. In any case two adversarial processes, the use of any kind of resource use and their rehabilitation or/and reproduction have to be balanced in space and time, and such balancing is needed in additional resources be it new knowledge or artificially-constructed materials. The more any production process is modernized the more it is becoming less physical labor-consuming and more knowledge-consuming and metabolic in its character.

More than that, modern market economy aimed at gaining more profit had invented an instrument for raising capital accumulation and, as a result, for intensification of risks production. Risks are recently produced by a consumer society, that is, by a socially-constructed system of production of new, usually surplus needs. Not of vital requirements but of excessive and permanent consumption in any form. As the Global Risks Reports clearly showed, the most dangerous and all-embracing risk is the global warming that is a direct result of long-term nature exploitation and raising consumer society. It's characteristic for the documents like the Global Risks Report 2018, to miss in their analysis any negative consequences of rapid growth of modern market economy if they are the outcomes of it. Such reports are mainly analyses natural and social consequences of the use of new technologies and information-communication networks in particular.

\section{RISK SPECIFICITY IN A GLOBAL SOCIETY}

Some Western sociologists are usually equalized globalization process with transnational practices of global stakeholders. They distinguish three levels of it. 'The first level is inhabited by transnational corporations and economic organizations like the WTO, IMF and the World Bank...The second level of transnational practice is largely political, represented by the transnational capitalist class.' A third level 'is transnational cultural practice.'(Hofmeister and Breitenstein, 2008: 483). It's indicative that these authors doesn't even mention a social level represented by numerous social movements, local and global, as well as grassroots and any other forms of civil activism. These authors have referred to the principle of the power of the switch of media channels and transformation of their content as a mighty instrument of shaping of mass consciousness (Arsenalt and Castells, 2008).

More than that, the above two authors as many others stated that 'western-style capitalism dominates the rules of the economic game, western-style capitalist countries set standards for political contexts that other nations feel obligated to adopt in order to compete' (Hofmeister and Breitenstein, 2008: 482).To my mind, the modern global picture and global processes are much more complex and diverse. India and China demonstrate exponential growth. Russia despite inner economic crisis and outside sanctions has become economically sustainable and politically independent; and Brazil and other Latin America countries are struggling against the domination of the rich North. Besides, there are the BRICS, the ShOC and other counterbalancing inter-state organizations.

But the risk specificity in global society has much more profound foundations. Hereafter I'll refer to empirical study of global risks conducted annually by international team of the World Economic Forum in the years of the 2008-2018. I consider this long-term research as an outstanding achievement of world interdisciplinary community and the point of department of my further speculations and suggestions. My criticism addressed to this exclusive international study has the only one aim: to make an attempt to point to some lacunas in the above project and to offer some additional directions of further research. I'll mainly refer to Figures 1-3 of the Risks Report 2018 as the most visible explications of the above project concept. My considerations are based on my long-term research in natural and man-made catastrophes and some case-studies of modern international conflicts and wars in Syria and mass migration from the Near East and the North Africa to Europe. 
First, all risky networks indicated in the Figures no 1-3 are not always have direct outcomes, they maybe indirect or even false, i.e. dramatized. Such artificially-constructed false news is usually shortlived. Besides, all ties between networks are also not direct as well. My study of the siege of Aleppo (Syria) in 2017 showed a variety of networks, direct and indirect, quick and in the form of long-time pressure, networks resulted from direct clashes of adversaries and distanced and usually overt pressure by mass-media. The networks may be constructed by regular troops or by mobile unidentified military actors, etc. The network's overall mobility is their very important distinguishing feature.

Second, a time is a very important actor as such. There are several aspects of the time issue. It may be the network which signifies periodical or permanent pressure. Then, the very 'amount' of time in hands seriously depends on other resources in the same hands, of the time of their supply, use, manipulations with wastes, etc. The same picture is in a critical situation. The one thing is a transfer of financial aid by means of IT-networks and quite another is a supply with arms, food-staffs, medicine and various kind of humanitarian aid as well as a re-grouping of military forces, etc.

Third, I'm surprised that in the abovementioned figures and the text of the Risks Report 2018 there is no one word concerning a feedback (or using the Beck's term, a boomerang effect)of the networks indicated in all figures. But the basic principle of nature, human or technical activity is their reciprocal character. Of course, any response may be immediate or postponed, quick or slow, but it has to be. Anything happened in one part of the globe will have the feedback in its other parts. Thus, the temporhythms of ongoing global events have to be carefully investigated. Let me remind that the maxima 'the weakness is a strength' is theoretically and practically acute.

Fourth, network interactions may be symmetrical or asymmetrical what has not been taken into account in the above Report. In turn, the asymmetry response may be of two kinds using by the same networks (for example, by the IT-communications) or by entirely another ones (for example, by the use of economic or political measures). The asymmetrical approach presupposes the tempo-rhythms variations, for example, when a certain sanction is announced but suspended for indefinite time.

Fifth, in global reality we are dealing with a lot of forms of interaction, direct action and economic or political pressure, the actions pursue tactical or strategic aims; it may be the efforts pursuing the aim of building the unions or temporary alliances, etc. One should take into account that there are two opposite kind of network building: the direct, as it shown at Figures 1-3 or indirect in the form of allembracing and all-penetrating risks aimed at total restructuring of structural-functional organization of a certain collective actor.

Sixth, it follows that the very notion of actor and its networks is very unstable and sometimes uncertain and undetectable. The reason is that in the Figures 1-3 of the Report 2018 is hard to understand (and to identify) who had been an initial actor. Every point of departure of a particular network (for example, changing climate, degrading environment, increasing polarization of societies, rising of cyber dependency, etc.) has its particular actor or source of emergence. If one began to search each of them he'll finally find himself in a vicious circle. Once again, 'All connected with all', and so on.

Seventh, the building of the graphs like those which are shown at the Figures 1-3 is becoming much more problematic if one takes into account a multiplicity of metabolic processes that are permanently going on between all parts of any social organism. Metabolic processes are going on both in the very networks and at their intersections. These processes are of various kinds: social, political, economic as well as biochemical, biosocial, socio-technical and many others. Modern logistics is a process of coordination of the tempo-rhythms of diverse processes. It is surprising that those who call themselves the geopolitics didn't take into account a variety of metabolic processes that are literally totally embrace a global SBT-functioning. The study of global metabolic processes is of a paramount importance if we want to understand an actual 'mechanic' of relationships between various parts of global whole.

\section{Global Communication, Media ANd Local Life}

In the set of the Reports under consideration there is no one word about side-effects of global communication system and development of its network structure. Globalization is Janus-like and it has its dark side. First, as I've already stressed, modern risks are all-embracing and all-penetrating. It 
means the there is no absolutely safe places on the earth, there are more or less safe only. Second, the development of the Fourth industrial revolution leads to shrinking of labor market and changing of its structure. One of the Western theorists, K. Schwab (2016) foresees the growth of unemployment. Third, on the one hand, the development of digitalized network systems unites people across the world. But on the other hand, this system has its own language (rules, codes, etc.) and it gradually alienates a digitalized world from the rest one. Such alienation is especially risky today when a generational shift coincides with rapid digitalization of all spheres of human life. Under the impact of information-communication revolution a process of early socialization beyond the limits of family and local community is going on (Büchler-Neiderberger, 2010).

Fourth, Z. Bauman and many other western theorists of globalization calls modern society as an individualized one. But the dark side of this state of global restructuring is a decay of a family, clan and local community as basic social and cultural units of traditional and industrial society. It's characteristic to a majority of western works on global issues that there is nothing about local life, a specificity of its way of communication, man-nature relationships and other traditional forms of human existence. Fifth, mass-media is a mighty instrument of shaping mode of consumption and the way of life. Rapidly-changing media-pictures create a 'collage' mode of perception of quickly changing global reality. As a result, a man is rapidly turning from a relatively independent actor into an object of manipulation of forces that are out of his/her control. Sixth, the media are less and less informing but more and more constructing global and local events and trends. Therefore, the media is an instrument in the hands of global stakeholders for shaping of global geopolitics be means of constructing (often, dramatizing) global public opinion. The further the more the media has become a major instrument of shaping a man's mode of living during his/her life-span.

Seventh, being the global geopolitical stakeholders, the giant nation-states like India, China and Brazil as well as their alliances gradually adopt the rules of global market but remained culturally diverse. Nevertheless, an overall process of diminishing of natural and cultural diversity is rapidly going on. How to reconcile 'global' and 'local' in human development is still an open question.

\section{Global SBT-System as a Key POINT OF Risks ANAlysis}

If it is the system, any dichotomy approach like man-nature, rural—urban, we-they, etc. to the study of global risks and their consequences is not relevant for the analysis of global SBT-system evolution. I fully realize that such interdisciplinary approach is now contradicted with prevailing mono disciplinary trends backed by disciplinary and institutional barriers. But as one can see, the most promising achievements in industry, medicine, education and other spheres of human activity are based on interdisciplinary approach in science, design and geopolitical practice. The very fact of network structure of global risks and their transformable character testify in behalf of such approach. As it has been mentioned earlier, the all-embracing character of global information-andcommunication networks had 'compressed' various spheres of life and therefore strengthened this integrative effect. The existence of a set of global stakeholders doesn't contradict to the above statements.

As I'd mentioned earlier, 'the interdisciplinary and problem-oriented approaches, combination of topdown and bottom-up analyses, mutual interpretation of research findings of social, natural and technical sciences, focus on metabolic nature of processes within the SBT-systems and their inherently risky nature, a periodical emergence of critical situations, the phenomenon of "space inversion", the "follow the actor principle", the relativity of notions of actor and its environment, and a network nature of all SBT-systems are the main points of its analysis' (Yanitsky, 2016: 123).The global SBT-system is inherently risky because it is composed from qualitatively different subsystems, networks and the type of their relationships that have specific dynamics, tempo-rhythms of inner transformations and interactions with outer world, terms of their relative sustainability, etc.

The principal newness of an approach to the study of the SBT-systems offered here is that the life of its actors (matters, things, social agents, etc.) of modern industry products and wastes including informational ones being 'released' into an environment, including the biosphere, continues there their further metabolic transformations. As a result, the 'environment' in any of its form is becoming a mighty force shaping all social actors involved. In other words, any environment is a multi-sided biochemical-informational actor as well. Therefore, the socio-ecological metabolism is not mere 'exchange' by the information, substances, services, etc. and not an interaction between inert and 
living agents of a social process but an impact of the ones on the others. In this process the ones agents are growing or developing while the others are degrading and/or turning into wastes.

To my mind, we are on the eve of surmounting of global threshold of the biosphere relative sustainability. The further the more the population in any country will be dealt with the side-effects of this surmounting, using the Beck's term (Beck, 1994: 175).The 'further the modernization of modern societies proceeds, the more the foundations of industrial society are dissolved, consumed, changed and threatened' and, as Beck underscored, these processes are going without reflection, beyond knowledge and consciousness (Beck, 1994: 176). But as for me, it's not simply an overcoming a certain threshold it's the beginning of the global SBT-system instability and degradation with unknown regularities and prospects.

The global situation is aggravated by the growing opposition between scientific and expert knowledge and everyday experience of rank-and-file people, on the one hand and socially-constructed and barely false information disseminated by the mass-media, on the other hand. Sometimes, the more real situation is aggravated the more optimistic it is depicted by mass-media. Such trend is coincided with the moods of rank-and-file people who are not prepared to sharp changes in their mode of living.

Humanity recognizes very slow the above transformations and trends because they accustomed to interpret them in economic and political terms. And if they do see them, it doesn't mean that their reactions will be adequate since they were taught to believe that all issues will be resolved by technological means. Therefore creation of new technologies will strengthen in all spheres of human activity. It will be a struggle for limited resources between global and local stakeholders and not for nature and humanity protection. First of all it will be the resources of the World Ocean and then of the planets of the sun system. Unfortunately, an idea that our planet is overpopulated will be confirmed be the forced redistribution of diminishing amount of living areas and resources in favor of the richest. In sum, the globalization and the emergence of the global SBT-system stimulate the reflexive processes that is, according to Beck and Giddens, the processes of self-dissolution and self-endangerment of current industrial modernization or the 'ambivalence of modernity', according Z. Bauman. Or, using its modern version, it is an inevitable ecological crisis and short-termism of modern capitalist society (Von Weizsäcker and Wijkman, 2018).

\section{CONCLUSION}

It's a bit strange that many leading theorists of globalization processes didn't analyze them in network terms. Of course, they mentioned them from time to time but never put network analysis in the center of their theoretical speculations. As for me, under conditions of the Fourth industrial revolution and the emergence of global SBT-system the network analysis is absolutely necessary as well as a study of its inherently contradictory nature, dissolving processes and multisided metabolic transformations in space and time.

An actual global network structure is much more complicated than it is shown on Figures 1-3 of the Report 2018, its actors are of diverse nature, they are mobile and may combined in various ways that is impossible to present in any figures of 2-D format, as it has been done in the series of the above Risks Reports. The initial sources of risks under consideration cannot be identified, and it is the main shortcoming of the very interesting and provocative analysis presented in the set of the above Reports.

The results of my reflections are as follows.

First, the abovementioned structural schemes should be interrelated with a dominating type of industrial production and social reproduction that is with modern capitalist system and its basic laws and requirements. It means, in particular, that global network system is a secondary one in relation to modern capitalist system despite its all fluctuations.

Second, in turn it means that visual presentations of global networks are 'technological' ones. Such mode of presentation didn't take into account the key sources of global risks that are the main centers of power and influence that construct an actual picture of disposition of forces and its permanent transformations.

Third, accordingly the methods, forms and results of the struggle of global and regional stakeholders cannot be depicted in the frames of the methodology of research used in the series of the above Risks Reports. 
Fourth, the researchers of global processes and structures are needed in a more detailed and sophisticated epistemology and field-research instruments. Methodologically it will be more correct (and interesting) to develop initially an overall picture of the main centers of global power and influence, than to present the aims and ultimate goals of each of them, after then to explicate a disposition of global forces and finally to try to reveal and depict a map of points of their consent and disagreements.

Fifth, not only a spatial but a time-dimension of this multisided picture is the key ones in modern liquid world. But it doesn't necessarily mean that the time signifies the movement of the global SBTsystem forward. An opinion that two world wars mowed our world only forward is false. A coming global warming is the best example of a process of self-braking of the global SBT-system.

Sixth, a complex study of the macro, average and micro-processes of the global SBT-system coupled with overall biosphere turnover may give unexpected results. My hypothesis is that we'll see a lot of tough geopolitical conflicts with hard social consequences and natural damages in a foreseeable future (see, for example, Sassen, 2016).

Seventh, the sociologists and other humanitarians have to recognize an importance of metabolic studies between natural, social and artificially-constructed worlds as well as the phenomenon of social metabolism as such. A 'bare' interactionism should be replaced by in-depth analysis of a variety of metabolic processes.

Eighth, all this means that interdisciplinary concept of network structure of a global whole should be at the first lines of geopolitical studies of national and international teams.

Ninth, the interdisciplinary approach will be successful only with close collaboration with modern grassroots activists. I underline the term 'modern' because recent civil activists are usually not only has the higher education but they are well experienced persons capable to think locally and globally. Of course, I mean not members of the Green parties but first of all who are consciously have become the environmental activists. Nowadays, an interest of the sociologists to informal practices is revitalizing (see, for example, Boudreau and Davis, 2017).

And finally, we have to pay much more attention to the emergence of a 'parallel' i.e. virtual society in which networks may be constructed and structured differently, surplus production may be replaced by mining and other forms of a capital accumulation, etc. New technologies only begin to show their prospects, potentials and risks.

\section{REFERENCES}

[1] Adam B., Beck U. and Van Loon J., eds. (1994).Positioning Risk. London: Sage.

[2] Arsenault A. and Castells M. (2008). Switching Power: Rupert Murdoch and the Global Business of Media Politics. International Sociology 23(4): 488-513.

[3] Bauman Z. (2001).On Glocalization: Or Globalization for some, localization for some others, in: Bauman Z. The Bauman Reader. Malden, MA: Blackwell Publishers Inc., pp. 298-311.

[4] Bauman Z. (2001a). The Individualized Society. London: Polity.

[5] Beck U. (1994). Self-Dissolution and Self-Endangerment of Industrial Society: What Does This Mean? In: Beck U., Giddens A. and Lash S. Reflexive modernization. (1994). Politics, Tradition and Aesthetics in the Modern Social Order. Stanford: Stanford University Press.

[6] Beck U. (1999). World Risk Society. Malden, MA: Polity Press.

[7] Boudreau J.-A.and Davis D.E. (2017). Introduction: A processual approach to informatization. Current Sociology, Vol.65, No 2, Monograph (1): 151-166.

[8] Büchler-Neiderberger D. (2010).Childhood Sociology - Defining the State of Arts and Ensuring Reflection. Current Sociology, 58 (2): 155-163.

[9] Hofmeister H. and Breitenstein A. (2008).Transnationalization and Globalization. International Sociology 23(4): 480-487.

[10] Lash S., Szerszynski B. and Wynne B. (1996). Risk, Environment and Modernity: Towards a New Ecology. London: Sage.

[11] The Global Risks Report 2018. 13th Edition. Geneva: Springer. Available at: http://www3 .weforum.org /docs/WEF_GRR18_Report.pdf

[12] Sassen S. (2016). A Massive Loss of Habitat: New Drivers for Migration. Sociology of Development. Vol. 2, no 2: 204-233. http://soc.dev.ucpress.edu/content/2/2/204 
[13] Schwab K. (2016). The Fourth Industrial Revolution. Geneva: World Economic Forum.

[14] Urry J. (2008).Mobilities. Cambridge: Polity Press.

[15] Therborn J. (2000). Three concepts of globalization. International Sociology, Vo. 15 (2): 180-196.

[16] Therborn.(2013). 'Global Cities', World Power, and G20 Capital Cities, in: Fujigita K., ed. 2013. Cities and Crisis.New Critical Urban Theory. London: Sage: 51-82.

[17] Urry J. (2011).Climate Change and Society. Cambridge: Polity Press.

[18] Von Weizsäcker E.U.andWijkman A.(2018).Come On! Capitalism, Short-termism, Population and the Destruction of the Planet. New York: Springer. DOI 10.1007/978-1-4939-7419-1

[19] Yanitsky O. (2012). A Primary Eco-Structure: The Concept and its Testing. Social Analysis, Vo.2 No 2 , pp. 7-24.

[20] Yanitsky O. (2016). Socio biotechnical systems: A New Approach to Man-Nature Interactions, In: On Globalization and its Environmental Consequences. The Yanitsky Reader II. Moscow: Institute of Sociology RAS. Available at: http://www.isras.ru/index.php?page_id1198\&id=4603

Citation: Oleg N. Yanitsky. "Global Risks Networks: A New Field of Interdisciplinary Studies." International Journal of Research in Sociology and Anthropology (IJRSA), vol 4, no. 1, 2018, pp. 8-15. doi:http://dx.doi.org/10.20431/2454-8677.0401002.

Copyright: (C) 2018 Authors. This is an open-access article distributed under the terms of the Creative Commons Attribution License, which permits unrestricted use, distribution, and reproduction in any medium, provided the original author and source are credited. 